\title{
Dietary nutrient intake related to higher grade cervical intraepithelial neoplasia risk: a Chinese population-based study
}

Zhe Wang ${ }^{1}$, Aimin Yang ${ }^{2}$, Jing Yang ${ }^{1}$, Weihong Zhao ${ }^{1}$, Zhilian Wang ${ }^{1}$, Wei Wang ${ }^{1}$, Jintao Wang ${ }^{3}$, Jinghui Song ${ }^{4}$, $\mathrm{Li} \mathrm{Li}{ }^{5}$, Weiguo Lv ${ }^{6}$, Dongyan Li ${ }^{1}$, Huiqiang Liu' ${ }^{1}$, Chen Wang ${ }^{7}$ and Min Hao ${ }^{* *}$

\begin{abstract}
Background: Dietary nutrient intake plays a significant role in carcinogenesis. Few studies have investigated the association between dietary nutrient intake and cervical intraepithelial neoplasia (CIN) risk in China.

Methods: Data on 2304 women from an ongoing cohort comprising 40,000 women from China in 2014 were included. Study randomly selected 218 out of 2304 people as subjects during 2019. All participants were surveyed through in-person interviews, physical examinations, and laboratory tests. Clinical data were obtained from physical examinations and laboratory tests. Dietary intakes were assessed using a semiquantitative food frequency questionnaire. Nutrition intakes from 26 food sources were calculated using a comprehensive validated database. Descriptive statistics were used to describe the frequency and proportion, and mean and standard deviation of the demographic characteristics. Characteristics were examined for significant differences, and Pearson chi-square tests were used for categoric variables. Logistic regression was used to obtain odds ratios (ORs) and confidence intervals (Cls) for CIN risk in each nutrient intake quartile relative to that in the highest quartile.
\end{abstract}

Results: The food frequency questionnaire exhibited acceptable reproducibility and reasonable validity in assessing nutrient intakes among these women. After adjusting for multiple confounders, several dietary nutrients showed significant associations with CIN2+ risk. Low dietary folate intake was associated with the risk of CIN2+ (first versus fourth quartile: $\mathrm{OR}=1.55,95 \% \mathrm{Cl} 1.03-2.33)$. Similar results were also observed for vitamin $\mathrm{B} 6(\mathrm{OR}=1.63,95 \% \mathrm{Cl}$ $1.08-2.46)$, vitamin $\mathrm{C}(\mathrm{OR}=1.59,95 \% \mathrm{Cl} 1.05-2.42)$, niacin $(\mathrm{OR}=1.65,95 \% \mathrm{Cl} 1.08-2.51)$, and vitamin $\mathrm{K}$ (second versus fourth quartile: $\mathrm{OR}=1.60,95 \% \mathrm{Cl} 1.05-2.44)$.

Conclusions: Low folate; vitamin B6, C, and K; and niacin intakes were associated with CIN2+ risk. Nutrients may influence the development of higher grade CIN and cervical cancer.

Trial registration The study was registered in the Chinese Clinical Trial Register (ChiCTR-ROC-15006479) (https://www. chictr.org.cn).

Keywords: Nutrient intake, Cervical intraepithelial neoplasia, China, Cross-sectional analysis, Vitamin

*Correspondence: 2yuanhaomin@163.com

1 Department of Obstetrics and Gynecology, Second Hospital of Shanxi Medical University, 382 Wuyi Rd, Taiyuan 030001, Shanxi, China

Full list of author information is available at the end of the article

\section{Background}

Cervical cancer has serious implications for women's health, and remains the most common female malignancy in virtually all low-resource countries [1]. Globally, almost 530,000 women experience cervical disease development every year, with an associated mortality of 265,000 [2]. Although human papilloma virus (HPV) original author(s) and the source, provide a link to the Creative Commons licence, and indicate if changes were made. The images or other third party material in this article are included in the article's Creative Commons licence, unless indicated otherwise in a credit line to the material. If material is not included in the article's Creative Commons licence and your intended use is not permitted by statutory regulation or exceeds the permitted use, you will need to obtain permission directly from the copyright holder. To view a copy of this licence, visit http://creativecommons.org/licenses/by/4.0/. The Creative Commons Public Domain Dedication waiver (http://creativeco mmons.org/publicdomain/zero/1.0/) applies to the data made available in this article, unless otherwise stated in a credit line to the data. 
vaccination has helped in reducing the incidence or prevalence associated with the disease, country-wide vaccination is difficult in developing countries owing to the associated high expenses [3]. The diversification of preventive measures is required.

Cervical carcinogenesis is related to high-risk HPV (HR-HPV) infection [4]. Recent studies have found that the risk factors of cervical intraepithelial neoplasia (CIN) include not only persistent HPV infection and other well studied risk factors such as socioeconomic status, smoking, age at first intercourse, high parity, and oral contraceptive use [5-13], but also dietary nutrient intake, daily habits, customs, and the presence of vaginitis and an abnormal vaginal $\mathrm{pH}$ [14]. The intake of fruits, vegetables, and vitamin-rich foods has the potential to prevent HPV infection [14-16]. Dietary nutrients also act as antagonists for CIN risk [17].

Folate, a water-soluble B vitamin, is essential for the synthesis of nucleotides and DNA hypomethylation [18]. A previous study found no association between dietary folate intake and CIN risk [19]. However, other studies observed conflicting results [20-22]. Vitamin B6 reportedly aids in the regulation of the immune system, which is associated with cancer risk [23]. Studies have reported significant associations between dietary vitamin B6 intake and CIN [20, 24]. Vitamin $\mathrm{C}$ intake is associated with cervical disease development [25], and can protect against CIN and invasive squamous carcinoma $[15,17,26,27]$. Vitamin $\mathrm{K}$ has anticancer effects [28, 29], and induces cancer cell apoptosis [30]. Recent studies have also found that niacin can protect against cancer recurrence [31, 32].

Shanxi province is a landlocked and economically backward region. The diet of its residents mainly includes staple food, and their vegetable intake is low. The morbidity associated with cervical cancer in Shanxi is 10 times higher than the national average [33]. The previous study showed that the intake of folate-rich food could reduce cervical cancer risk [34]. The plasma nutrient concentrations among the residents of Shanxi are lower than those among people from other areas [21]. It is unclear whether dietary nutrition intake can affect CIN incidence. Accordingly, the current study initiated a large population-based cervical cancer screening program and a prospective cohort study in the Shanxi CIN Cohort. The current study evaluated the associations of the intakes of dietary nutrients such as folate, vitamin B6, vitamin C, vitamin $\mathrm{K}$ and niacin, with $\mathrm{CIN}$ risk using categorical analyses.

\section{Methods}

\section{Study population}

The data in this study are based on the the baseline survey of the Shanxi CIN Cohort Study in 2014, which includes 40,000 eligible local women from the Shanxi province, China. The rationale, design, and methods of the Shanxi CIN Cohort Study have been detailed elsewhere [21, 35, 36]. Briefly, the study conducted a free cervical cancer screening for eligible women who were permanent residents of the two counties in Shanxi province during 2014.

A total of 40,000 participants were included. All participants were surveyed using a demographic characteristics-related questionnaire and a Pap test based on liquid-based cytology (LBC). Participants with abnormal Pap test results were examined by colposcopy and histopathology. A total of 2769 women were diagnosed as having atypical squamous cells of undetermined significance (ASC-US) and above, and 78 were excluded (68 refused to participate and 10 showed glandular cell abnormalities). Of the 2691 participants for whom pathologic results were available, 1890 had negative results who with abnormal cytology with currently normal histology. Finally, 564 participants were histologically diagnosed with CIN grade 1 (CIN1), and 237 participants with CIN2 or above $(\mathrm{CIN} 2+)$. Of the 1890 women with negative pathologic results, 1503 participants were included in the study analysis after the exclusion of 387 women who had not fully completed the three parts of the medical examination, including an in-person interview, a physical examination, and a clinical examination. A sample of 2304 women with a mean age of $49.2 \pm 9.1$ years was enrolled in the present study, Detailed flowchart of this study have been published elsewhere [36]. All inspections and detections were performed under double-blind conditions. The study was approved by the ethics committee of the Second Hospital, Shanxi Medical University and written informed consent was obtained from the participants.

\section{Data collection}

Several types of data was collected in this study, including questionnaire-related data obtained from in-person interviews, and clinical data from physical examinations, laboratory tests and biospecimen collection. In-person interviews were conducted by trained interviewers using a standardized questionnaire. Demographic information included age; years of education; yearly income; tobacco smoking; age at menarche; menopause status; years of intrauterine device (IUD) use; and sexual activity in the menstrual period. Participants completed a 26-item food frequency questionnaire (FFQ). Clinical data were obtained from physical examinations and laboratory tests, including Pap tests, vaginal $\mathrm{pH}$ tests, and cervical 
biopsies. Data on IUD use, squamous-columnar junction (SCJ) visibility, had gynecologic surgery and vaginitis were also collected. Participants provided biological samples that were stored for future work (blood and cervical tissue specimens).

\section{Clinical laboratory tests}

All Pap tests were performed using the LBC method. At least two cytopathologists from the Second Hospital of Shanxi Medical University evaluated the cytologic results, which were reported using Bethesda System (TBS) 2001 terminology. All abnormal cytology slides were further reviewed for quality control by a senior cytopathologist who was blinded to the previous pathology results if the case was of type ASC-US+ or worse. Gynecology specialists from the Second Hospital of Shanxi Medical University identified patients with an abnormal cervix, and biopsy was performed by colposcopy (SLC-2000 device, Shenzhen Goldway Company) according to a standard protocol $\leq 12$ week after the Pap test. Gynecology specialists divided the cervix into quadrants and examined each quadrant. All visually abnormal areas were biopsied, and the quadrants without a visible lesion were biopsied at the SCJ ("random biopsy"). Endocervical curettage was also performed. The cases were classified as negative, CIN1, CIN2, CIN3, or squamous cell carcinoma (SCC). In the end, the pathologists performed a doubleblinded observation of the Pap test results after diagnosis based on the cervical biopsy or endocervical curettage tissue specimens. If two pathologists presented different diagnoses, the samples were reviewed by another senior pathologist. The three pathologists reviewed difficult or equivocal cases together to arrive at a consensus on diagnosis.

HPV genotyping by HybriMax was performed using residual Pap test specimens with the HPV GenoArray Test Kit (HybriBio Ltd), and cases were divided into the high-risk HPV infection group and "others" (including low-risk HPV and negative cases). This assay can identify 21 types of HPV, including 15 high-risk types $(16,18$, $31,33,35,39,45,51,52,53,56,58,59,66$, and 68$)$. The low-risk HPV types include types $6,11,42,43,44$, and CP8304, which were identified using the flow-through hybridization technique performed with a TC-96/G/ H6 HPV DNA Amplification Analyzer and an HMM-2 fast nucleic acid molecule hybridization instrument (HybriBio Ltd).

Vaginal $\mathrm{pH}$ testing was performed with a $\mathrm{pH}$ test paper (Marok Darmstadt Germany) with the residual Pap test specimens (2304); vaginal $\mathrm{pH}$ values exceeding 4.5 were considered abnormal [37]. Cases were divided into two groups based on the $\mathrm{pH}$ results: normal $\mathrm{pH}$ group $(>3.8$, and $<4.5)$ and abnormal $\mathrm{pH}$ group $(\geq 4.5)$.

\section{Dietary nutrient assessment}

The measurement of individuals' dietary nutrients intake were calculated based on a food frequency questionnaire (FFQ) obtained from in-person interview. The FFQ in this study was nested in the standardized and structured epidemiological questionnaire of the Shanxin CIN Cohort study. The $24 \mathrm{~h}$ dietary recall dietary data were collected by trained interviews who recorded amounts of all the food items. The FFQ was designed based on the China Health and Nutrition Survey (CHNS) [38, 39]. Detailed descriptions of the dietary measurements have been published elsewhere [38, 40]. A total of 26 items food was included in the FFQ, which are main food sources for participants in this study. Based on a Chinese National Nutrition Survey in 2002, ten of 26 items food already account for about $85 \%$ of the total dietary intake in Chinese population. The FFQ included 26 food items: wheat flour, soybean, cabbage, egg, oats flour, bean curd, celery, cow milk, buckwheat flour, dried bean curd, spinach, pork liver, rice, broad bean, Chinese chives, sunflower seed, millet, potato, carrot, jujube, maize, mushroom, pumpkin, banana, liquor, and tea.

The FFQ data was analyzed using the US Department of Agriculture's 1994-1996 Continuing Survey of Food Intakes [41]. The average food intake of individuals (gram/day) was calculated. Each nutrients intakes (grams/milligrams/micrograms per day) were then calculated by multiplying the daily food consumption amount ( $\mathrm{g}$ per day) by the median nutrition content $(\mathrm{g}$ per $100 \mathrm{~g} / \mathrm{mg}$ per $100 \mathrm{mg} / \mu \mathrm{g}$ per $100 \mu \mathrm{g}$ of food) of that food. The nutrition values from all other FFQ items were combined to obtain the total daily nutrition values. However, the study did not collect the dietary supplement information in this study because the prevalence of nutrients supplement use is very low in Chinese population [42]. The study estimated the level of each dietary nutrient intake as the following equation: Total daily nutrition value $=$ total amount of each food $(\mathrm{g} / \mathrm{mg} / \mu \mathrm{g}) /$ (day) * intake value per $100 \mathrm{~g}$, per $100 \mathrm{mg}$, and per $100 \mu \mathrm{g}$. Total nutrition intake $(\mathrm{g} / \mathrm{mg} / \mu \mathrm{g}$ per day) was determined by calculating the sum of the daily nutrition values.

\section{Assessing the test-retest reliability and relative validity of the FFQ}

Randomly selected 218 out of 2304 people as subjects. The study started from January 2019 and lasted for the subsequent six months. During the study period, three consecutive 24-h studies (24-h) were conducted every three months. The first FFQ was collected during the first 24-h in January 2019. FFQ1 was collected after 3 months in March 2019, and FFQ2 was collected after 6 months in June 2019. The 'weight estimation (WE)' method for 
assessing food consumed for evaluation was estimated by the respondents for the weight of each food they

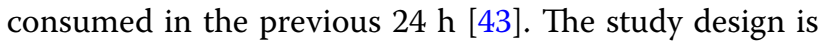
shown in Additional file 1: Fig. 1. Each participant was asked to provide the name and amount of food consumed during the previous $24 \mathrm{~h}$. If the previous day was a special day, for reasons such as banquets or travel, et al., current study would record food consumption $24 \mathrm{~h}$ ago, or choose another day to interview participants by telephone. Subjects were not informed of the results until the night before the interview. Record the amount of food mixed with a plate. According to the definition of food quality standard, recalled food is assigned to the corresponding food group.

For fruits consumed, the subjects were required to select the corresponding pictures representing the different sizes of each fruit and record the corresponding estimated weight (in grams). For commercial projects, such as sliced bread, cakes, packaged biscuits, pies and dumplings, record the unit weight (in grams) of the project. Trained interviewers manage FFQ and $24 \mathrm{~h}$ through face-to-face interviews. Immediately check all records and resolve any ambiguities in the subject. During the whole study period, each participant had his own interviewer. Participants who did not satisfactorily complete the FFQs or missed more than one out of the four 24-h were excluded from the analyses. Subjects with implausible energy intakes $(<500 \mathrm{kcal}$ or $>5000 \mathrm{kcal})$ were also excluded as described by previous studies. Extreme values were examined and excluded. A decision about whether or not to exclude the record from analyses was made according to the original FFQs and/or 24-h [44]. The validity of the FFQ methods was assessed by comparing the nutrient intakes derived from the FFQs. A 3-month FFQ was collected from the same subjects after administration of the first interviewer-administered FFQ.

\section{Statistical analysis}

Descriptive statistics were used to describe the frequency and proportion, and mean and standard deviation of the demographic characteristics. Participants' characteristics were examined for significant differences with a Pearson's chi-squared test for categoric variables. A logistic regression model was used to calculate the odds ratios (ORs) and their confidence intervals (CIs) for CIN risk in each nutrient intake quartile relative to that in the highest quartile. Tests for a linear trend across increasing quartiles of nutrient intakes were performed by assigning the medians of each nutrient intake to quartiles treated as continuous variables.

Analyses were adjusted for potential confounders. The first model was unadjusted. Next, adjusted for age $(<30$, $30-39,40-49,50-59$, and $>60$ years), years of education
$(<6,7-9$, and $>9$ years), yearly income $(<10,000,10,000-$ 30,000 , and $>30,000 ¥$ ), tobacco smoking (yes and no), age at menarche $(<13,13-<15,15-<17$, and $>17$ years $)$, menopause status (yes and no), IUD use (yes and no), years of IUD use ( $<10$ and $\geq 10$ years), sexual activity in the menstrual period (yes and no), history of undergoing a gynecologic surgery (yes and no), and presence of vaginitis (yes and no). In the final multivariable analysis, added other potential clinical confounders, including high-risk HPV (positive and negative), SCJ visibility (fully visualized and not fully visualized), and vaginal $\mathrm{pH}$ $(<4.5$ and $\geq 4.5)$.

The current study performed cross-sectional analyses with three knots (25th, 50th, and 75th percentiles) of the 2304 women to examine the association between logtransformed dietary intake levels and CIN risk. The study did not explore the association between dietary intake and SCC risk because of the limited number of SCC cases $(n=19)$. Statistical analyses were performed using SAS software version 9.3. All reported $P$ values were twosided, with a significance level of 0.05 .

\section{Results}

The characteristics of the participants $(n=2304)$ are shown in Table 1 . The proportions of women with CIN1 were $24.5 \%(\mathrm{n}=564)$, with CIN2+ (included CIN 2, CIN 3, and SCC, respectively) were accounted for $10.3 \%$ $(n=237)$ of all the cases. CIN and higher grade disease cases accounted for $34.8 \%(n=801)$ of all the cases. and The median ages of the women without CIN, CIN1, and CIN2+ were 51, 51, and 46 years, respectively. Women with CIN2+ were likelier to be $40-49$ years old $(P<0.05)$, experience earlier menarche $(P<0.05)$, and have HPV infection $(P<0.05)$. The number of women with CIN2+ in menopause was also low $(P<0.05)$. However, in terms of education level, yearly income, IUD use, tobacco smoking, vaginal $\mathrm{pH}$, vaginitis, gynecologic surgery, sexual activity in the menstrual period, and SCJ visibility, no significant differences were observed across the CIN groups.

Table 2 shows the median dietary nutrient intake in patients without CIN as well as in those with CIN1 and CIN2+. Women with CIN2+ were likelier to have lower dietary nutrient intakes. Figure 1 and Table 3 show the associations between dietary nutrient intake and CIN2+ risk among the 2304 women. Even after complete adjustment, the intakes of most nutrients continued to show significant associations with CIN2+ risk. The study took the fourth quintile as the reference. Compared with the 4th quartile of folate intake, the multivariable-adjusted ORs (95\% CI) for CIN2+ risk were 1.55 (1.03-2.33), 1.18 (0.77-1.79), 0.94 (0.61-1.46), 1.00 (reference), respectively. 
Table 1 Demographics of 2304 Chinese women by cervical histological examination ${ }^{\mathrm{a}}$

\begin{tabular}{|c|c|c|c|c|c|}
\hline Characteristics & Total & Without CIN & CIN1 & $\mathrm{CIN} 2+^{c}$ & $P$ value $^{\mathrm{d}}$ \\
\hline No. of participants (\%) & $2304(100.0)$ & $1503(65.2)$ & $564(24.5)$ & $237(10.3)$ & \\
\hline \multicolumn{6}{|l|}{ Age (years) } \\
\hline$<30$ & $58(2.5)$ & $36(2.4)$ & $19(3.4)$ & $3(1.3)$ & \\
\hline $30-39$ & $284(12.3)$ & $180(12.0)$ & $63(11.1)$ & $41(17.3)$ & \\
\hline $40-49$ & $711(30.9)$ & $441(29.3)$ & $175(31.0)$ & $95(40.1)$ & 0.041 \\
\hline $50-59$ & $970(42.1)$ & $666(44.3)$ & $231(41.0)$ & $73(30.8)$ & \\
\hline$>60$ & $281(12.2)$ & $180(12.0)$ & $76(13.5)$ & $25(10.5)$ & \\
\hline \multicolumn{6}{|l|}{ Education (years) } \\
\hline $0-6$ & $472(20.5)$ & $309(20.6)$ & $117(20.7)$ & $46(19.4)$ & \\
\hline $7-9$ & $996(43.2)$ & $630(41.9)$ & $239(42.4)$ & $127(53.6)$ & 0.047 \\
\hline$>9$ & $836(36.3)$ & $564(37.5)$ & $208(36.9)$ & $64(27.0)$ & \\
\hline \multicolumn{6}{|l|}{ Yearly income $(¥)$} \\
\hline$<10,000$ & $262(11.4)$ & $173(11.5)$ & 65 (11.5) & $24(10.1)$ & \\
\hline $10,000-30,000$ & $1119(48.6)$ & $738(49.1)$ & $255(45.2)$ & $126(53.2)$ & 0.763 \\
\hline$>30,000$ & $923(40.1)$ & $592(39.3)$ & $244(43.3)$ & $87(36.7)$ & \\
\hline Tobacco smoking & $49(2.1)$ & $29(1.9)$ & $12(2.1)$ & $8(3.4)$ & 0.063 \\
\hline Menopause status & $1174(51.0)$ & $803(53.4)$ & $293(52.0)$ & $78(32.9)$ & 0.001 \\
\hline \multicolumn{6}{|l|}{ High-risk HPV ${ }^{f}$} \\
\hline Positive & $755(32.8)$ & $429(28.5)$ & $168(29.8)$ & $158(66.7)$ & $<0.001$ \\
\hline Negative & $1549(67.2)$ & $1074(71.5)$ & $396(70.2)$ & $79(33.3)$ & \\
\hline \multicolumn{6}{|l|}{ Age at menarche (years) } \\
\hline$<13$ & $308(13.4)$ & $181(12.0)$ & $93(16.5)$ & $34(14.3)$ & \\
\hline $13-<15$ & $739(32.1)$ & $466(31.0)$ & $180(32.0)$ & $93(39.2)$ & 0.028 \\
\hline $15-<17$ & $654(28.4)$ & $452(30.1)$ & $133(23.6)$ & $69(29.1)$ & \\
\hline$>17$ & $603(26.2)$ & $404(26.9)$ & $158(28.0)$ & $41(17.3)$ & \\
\hline IUD' use & $1081(46.9)$ & $735(48.9)$ & $231(41.0)$ & $115(48.5)$ & 0.892 \\
\hline \multicolumn{6}{|l|}{ Years of IUD use (years) } \\
\hline$<10$ & $1632(70.8)$ & $1037(69.0)$ & $426(75.5)$ & $169(71.3)$ & 0.287 \\
\hline$\geq 10$ & $672(29.2)$ & $466(31.0)$ & $138(24.5)$ & $68(28.7)$ & \\
\hline \multicolumn{6}{|l|}{$\mathrm{SC} \mathrm{J}^{\mathrm{h}}$ visibility } \\
\hline Fully visualized & $646(28.0)$ & $382(25.4)$ & $185(32.8)$ & $79(33.3)$ & 0.114 \\
\hline Not fully visualized & $1658(72.0)$ & $1121(74.6)$ & $379(67.2)$ & $158(66.7)$ & \\
\hline \multicolumn{6}{|l|}{ Vaginal pH } \\
\hline$<4.5$ & $514(22.3)$ & $341(22.7)$ & 106(18.8) & $67(28.3)$ & 0.228 \\
\hline$\geq 4.5$ & $1790(77.7)$ & $1162(77.3)$ & $458(81.2)$ & $170(71.7)$ & \\
\hline Had gynecologic surgery & $397(17.2)$ & $255(17.0)$ & $107(19.0)$ & $35(14.8)$ & 0.647 \\
\hline Had vaginitis & $140(6.1)$ & $82(5.5)$ & $38(6.7)$ & $20(8.4)$ & 0.108 \\
\hline Sexual activity in menstrual period & $56(2.4)$ & $39(2.6)$ & $9(1.6)$ & $8(3.4)$ & 0.549 \\
\hline
\end{tabular}

a Data were presented as number (\%) of participants

b CIN, cervical intraepithelial neoplasia. All CIN status is by histology

c CIN2+ included CIN 2, CIN 3 and SCC

d $P$ values for differences between groups were obtained from the chi-square test for categorical categoric variables

e Represent in terms of Chinese Renminbi (RMB)

f HPV, human papilloma virus

g IUD, intrauterine device

h SCJ, squamous-columnar junction 
Table 2 Dietary nutrition investigated based on a 26-item food frequency questionnaire among 2304 Chinese women in the Shanxi Cohort Study ${ }^{\mathrm{a}}$

\begin{tabular}{|c|c|c|c|c|}
\hline Element (intake/day) & Without CIN & CIN1 & CIN2+ & Total \\
\hline Folate ( $\mu \mathrm{g})$ & $382.8(298.8-727.2)$ & $383.4(300.3-804.8)$ & $358.9(283.8-836.5)$ & 381.0 \\
\hline Vitamin B1 (mg) & $1.5(1.1-2.7)$ & $1.4(1.2-2.9)$ & $1.3(1.1-2.6)$ & 1.5 \\
\hline Vitamin B2 (mg) & $1.4(1.1-2.7)$ & $1.4(1.1-2.8)$ & $1.3(1.0-2.8)$ & 1.4 \\
\hline Vitamin B6 (mg) & $2.1(1.7-3.8)$ & $2.1(1.7-4.0)$ & $1.9(1.6-4.2)$ & 2.1 \\
\hline Vitamin C (mg) & $62.9(45.8-135.9)$ & $63.8(47.6-143.3)$ & $59.4(43.2-148.2)$ & 62.8 \\
\hline Vitamin E (mg) & $8.6(4.2-21.8)$ & $9.0(4.9-21.5)$ & $8.8(5.4-21.7)$ & 8.8 \\
\hline Vitamin K $(\mu \mathrm{g})$ & $201.2(127.0-519.4)$ & $197.1(134.1-569.4)$ & $187.2(127.7-560.6)$ & 198.2 \\
\hline Niacin (mg) & $22.0(18.1-42.5)$ & $21.7(17.8-43.3)$ & $21.3(17.5-42.5)$ & 21.9 \\
\hline Dietary fiber (g) & $34.8(27.5-62.8)$ & $34.4(27.5-65.8)$ & $32.1(26.0-62.4)$ & 34.5 \\
\hline
\end{tabular}

${ }^{a}$ Data were presented as median with range

For vitamin B6, compared with the 4th quartile of vitamin B6 intake, the multivariable-adjusted ORs (95\% CI) for CIN2+ risk were $1.63(1.08-2.46), 1.33(0.88-2.01)$, 0.93 (0.60-1.44), 1.00 (reference), respectively. The current study observed an inverse association between dietary vitamin C intake and CIN2+ risk in the participants, compared with the 4th quartile of vitamin $C$ intake, the multivariable-adjusted ORs $(95 \% \mathrm{CI})$ for $\mathrm{CIN} 2+$ risk were 1.59 (1.05-2.42), 1.16 (0.75-1.79), 1.11 (0.72-1.71), 1.00 (reference), respectively. Dietary vitamin $\mathrm{K}$ intake was significantly associated with CIN2+ risk among the participants, compared with the 4th quartile of vitamin $\mathrm{K}$ intake, the multivariable-adjusted ORs $(95 \% \mathrm{CI})$ for CIN2+ risk were 1.30 (0.86-1.98), 1.60 (1.05-2.44), 1.24 (0.81-1.89), 1.00 (reference), respectively. An inverse statistically significant association was observed between dietary niacin intake and CIN2+ risk. Compared with the 4th quartile of niacin intake, the multivariableadjusted ORs $(95 \% \mathrm{CI})$ for CIN2+ risk were 1.65 (1.082.51), 1.32 (0.87-2.01), 1.09 (0.71-1.66), 1.00 (reference), respectively.

Additional file 2: Table 1 shows the associations identified between dietary nutrient intake and CIN2+ risk in the 2304 women through the logistic regression analyses. In adjusted mode, demographics, lifestyle habits, and other covariates were adjusted for, and added adjusted for 9 dietary nutrients. Low dietary vitamin $C$ intake was associated with the risk of CIN2+ were 1.89 (1.01-3.55), 1.33 (0.76-2.32), 1.22 (0.74-2.01), 1.00 (reference). Low dietary vitamin $\mathrm{K}$ was associated with the risk of CIN2+ were 1.87 (0.97-3.61), 2.18 (1.23-3.86), 1.43 (0.85-2.42), 1.00 (reference). High dietary vitamin B1 was associated with the risk of CIN2+ were 1.08 (0.49-2.41), 0.93 (0.501.74), 0.43 (0.24-0.78), 1.00 (reference).

Table 4 shows the associations identified between dietary nutrient intake and CIN1 risk in the 2304 women through the logistic regression analyses. In fully adjusted mode (Fig. 1), demographics, lifestyle habits, and other covariates were adjusted for. The study observed statistically significant associations between dietary vitamin B1 intake and CIN1 risk were 0.99 (0.74-1.34), 1.33 (1.00-1.77), 0.91 (0.69-1.19), 1.00 (reference). However, the current study did not observe statistically significant associations between dietary folate, vitamin B2, vitamin B6, vitamin $C$, vitamin $E$, niacin, and dietary fiber with CIN1 risk.

The current study also explored the association between each dietary nutrient intake and CIN risk which included CIN1 and CIN2+ (Fig. 1 and Additional file 3: Table 2). Similarly, the study observed the statistical significant associations between folate, vitamin B1, vitamin B2, vitamin B6, vitamin $\mathrm{C}$, vitamin $\mathrm{E}$, niacin, and dietary fiber and risk of CIN, however, non significant associations were observed.

In terms of FFQ validity are shown in Additional file 4: Table 3, The energy-adjusted, and de-attenuated correlation coefficients of the FFQs (FFQ1 and FFQ2) and the 24-h are presented. The energy-adjusted correlation coefficient for WE of FFQ1, $\mathrm{r}^{\mathrm{b}}(0.93-0.99)$; and the deattenuated coefficient, $\mathrm{r}^{\mathrm{c}}(0.78-0.95)$ when compared with the 24-h. The energy-adjusted correlation coefficient for WE of FFQ2, $\mathrm{r}^{\mathrm{b}}(0.90-0.99)$; the deattenuated coefficient, $\mathrm{r}^{\mathrm{c}}$ (0.45-0.97) when compared with the 24-h, which were a little less than those of FFQ1 versus the 24-h. In the retest reliability of FFQ, the The intra-class correlation coefficient (ICC) of nutrient intake derived from WE FFQs collected at 3-month intervals are shown in Additional file 4: Table 3. The intra-class correlation coefficient for FFQ1 of WE, ICC (0.67-0.94) when compared with the FFQ2. The correlation coefficients were all above 0.6. All nutrients in WE-FFQ have good correlation and agreement.

The current study additionally explored the associations between Age, Age at menarche, High-risk HPV, Menopause status and CIN2+ risk (Additional file 5: 

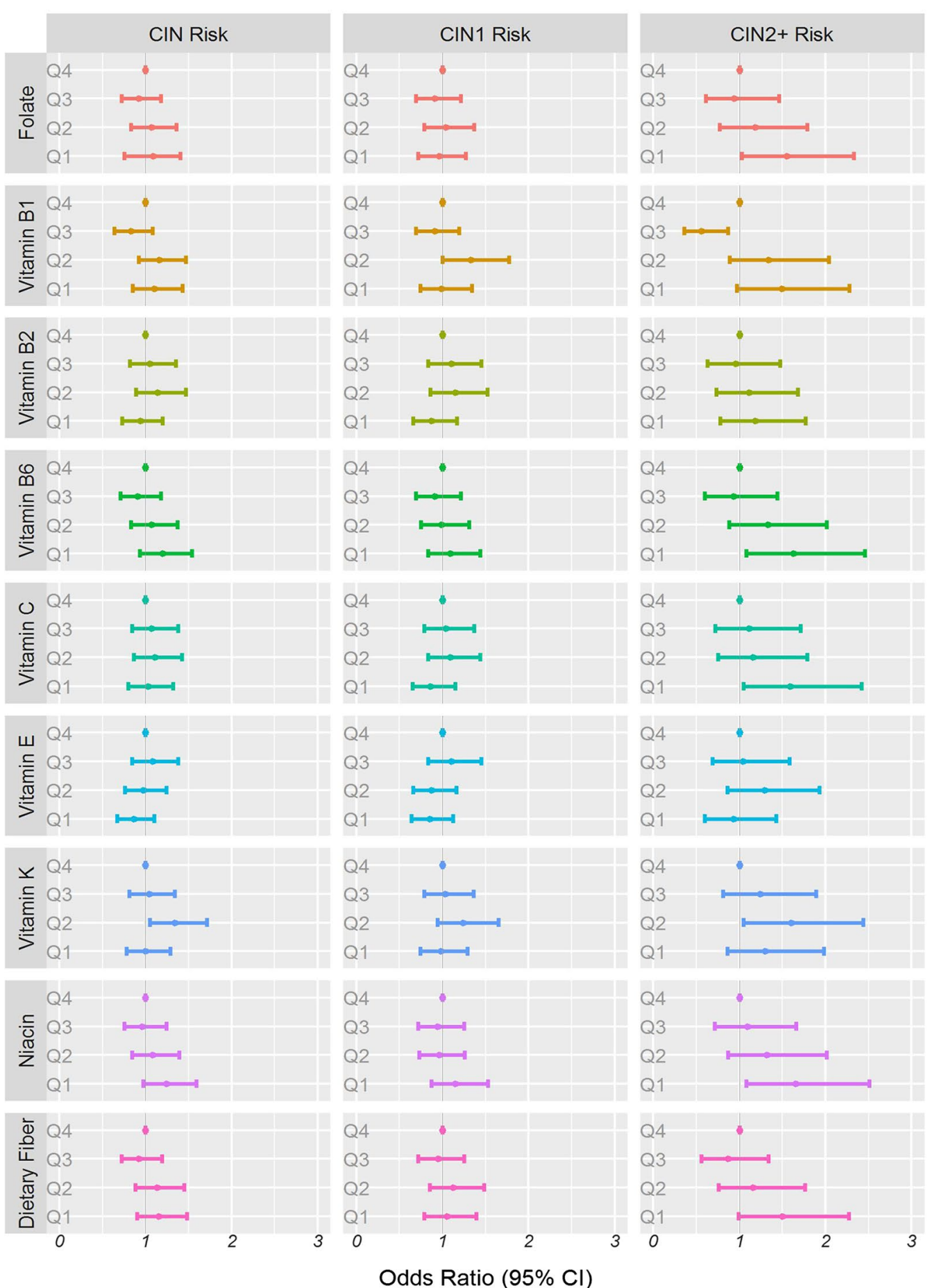

Fig. 1 The associations of dietary nutrient intake with the risk of cervical intraepithelial neoplasia, grade 1 cervical intraepithelial neoplasia and grade 2 cervical intraepithelial neoplasia and higher among 2304 women. The vertical lines signify the odds ratios and 95\% confidence intervals obtained in the multivariate logistic regression analysis after adjustment for age at the baseline, years of education, income, smoking status, age at menarche, menopause, HPV infection, intrauterine device use, years of intrauterine use, squamous junction status, vaginal pH, sexual activity during menstruation, and history of gynecologic surgery and vaginitis. The horizontal lines denote the quartiles of dietary nutrient intake for dietary folate, dietary vitamin B1, dietary vitamin B2, dietary vitamin B6, dietary vitamin C, dietary vitamin E, dietary vitamin K, dietary niacin, and dietary fiber 
Table 3 ORs and $95 \%$ Cls for quartiles of dietary nutrients intake with risk of cervical intraepithelial neoplasia grades 2 and above among 2304 women in the study ${ }^{a}$

Quartiles of dietary nutrients ${ }^{b}$

\begin{tabular}{|c|c|c|c|c|c|}
\hline & \multicolumn{5}{|c|}{ Quartiles of dietary nutrients ${ }^{b}$} \\
\hline & $\overline{\text { Q1 }}$ & Q2 & Q3 & Q4 & $P$-trend ${ }^{\mathrm{c}}$ \\
\hline \multicolumn{6}{|l|}{ Folate } \\
\hline Median intake ( $\mu \mathrm{g} /$ day) & 297 & 381 & 488 & 764 & \\
\hline No. of cases & 75 & 57 & 49 & 56 & \\
\hline Model 1 & $1.35(0.93-1.97)$ & $1.04(0.70-1.54)$ & $0.85(0.56-1.28)$ & 1.00 (reference) & $<0.001$ \\
\hline Model 2 & $1.49(1.01-2.21)$ & $1.08(0.72-1.62)$ & $0.89(0.58-1.35)$ & 1.00 (reference) & $<0.001$ \\
\hline Model 3 & $1.55(1.03-2.33)$ & $1.18(0.77-1.79)$ & $0.94(0.61-1.46)$ & 1.00 (reference) & 0.008 \\
\hline \multicolumn{6}{|l|}{ Vitamin B1 } \\
\hline Median intake (mg/day) & 1.1 & 1.4 & 1.9 & 2.7 & \\
\hline No. of cases & 72 & 72 & 35 & 58 & \\
\hline Model 1 & $1.24(0.84-1.82)$ & $1.41(0.96-2.06)$ & $0.59(0.39-0.90)$ & 1.00 (reference) & $<0.001$ \\
\hline Model 2 & $1.29(0.86-1.93)$ & $1.34(0.90-1.99)$ & $0.55(0.36-0.84)$ & 1.00 (reference) & $<0.001$ \\
\hline Model 3 & $1.49(0.97-2.28)$ & $1.34(0.89-2.04)$ & $0.56(0.36-0.87)$ & 1.00 (reference) & 0.017 \\
\hline \multicolumn{6}{|l|}{ Vitamin B2 } \\
\hline Median intake (mg/day) & 1.1 & 1.4 & 1.8 & 2.7 & \\
\hline No. of cases & 62 & 63 & 51 & 61 & \\
\hline Model 1 & $0.95(0.65-1.39)$ & $1.07(0.73-1.57)$ & $0.83(0.56-1.23)$ & 1.00 (reference) & $<0.001$ \\
\hline Model 2 & $1.07(0.72-1.58)$ & $1.12(0.75-1.66)$ & $0.92(0.61-1.38)$ & 1.00 (reference) & $<0.001$ \\
\hline Model 3 & $1.18(0.78-1.77)$ & $1.11(0.73-1.68)$ & $0.96(0.63-1.47)$ & 1.00 (reference) & 0.011 \\
\hline \multicolumn{6}{|l|}{ Vitamin B6 } \\
\hline Median intake (mg/day) & 1.7 & 2.1 & 2.6 & 3.9 & \\
\hline No. of cases & 69 & 65 & 47 & 56 & \\
\hline Model 1 & $1.27(0.87-1.86)$ & $1.13(0.77-1.66)$ & $0.83(0.55-1.25)$ & 1.00 (reference) & $<0.001$ \\
\hline Model 2 & $1.42(0.96-2.11)$ & $1.18(0.79-1.75)$ & $0.87(0.57-1.32)$ & 1.00 (reference) & $<0.001$ \\
\hline Model 3 & $1.63(1.08-2.46)$ & $1.33(0.88-2.01)$ & $0.93(0.60-1.44)$ & 1.00 (reference) & 0.002 \\
\hline \multicolumn{6}{|l|}{ Vitamin C } \\
\hline Median intake (mg/day) & 46.0 & 62.8 & 86.9 & 138.9 & \\
\hline No. of cases & 73 & 56 & 57 & 51 & \\
\hline Model 1 & $1.44(0.98-2.11)$ & $1.13(0.76-1.70)$ & $1.14(0.76-1.71)$ & 1.00 (reference) & $<0.001$ \\
\hline Model 2 & $1.56(1.05-2.33)$ & $1.16(0.76-1.76)$ & $1.15(0.76-1.75)$ & 1.00 (reference) & $<0.001$ \\
\hline Model 3 & $1.59(1.05-2.42)$ & $1.16(0.75-1.79)$ & $1.11(0.72-1.71)$ & 1.00 (reference) & 0.008 \\
\hline \multicolumn{6}{|l|}{ Vitamin $\mathrm{E}$} \\
\hline Median intake (mg/day) & 4.4 & 8.8 & 10.8 & 21.7 & \\
\hline No. of cases & 50 & 67 & 59 & 61 & \\
\hline Model 1 & $0.76(0.51-1.13)$ & $1.03(0.71-1.50)$ & $1.02(0.69-1.50)$ & 1.00 (reference) & $<0.001$ \\
\hline Model 2 & $0.92(0.61-1.40)$ & $1.13(0.77-1.66)$ & $1.08(0.72-1.60)$ & 1.00 (reference) & $<0.001$ \\
\hline Model 3 & $0.93(0.60-1.43)$ & $1.29(0.86-1.93)$ & $1.04(0.69-1.58)$ & 1.00 (reference) & 0.011 \\
\hline \multicolumn{6}{|l|}{ Vitamin $\mathrm{K}$} \\
\hline Median intake ( $\mu \mathrm{g} /$ day) & 133.0 & 194.0 & 285.0 & 534.0 & \\
\hline No. of cases & 61 & 71 & 51 & 54 & \\
\hline Model 1 & $1.12(0.77-1.65)$ & $1.42(0.96-2.10)$ & $1.01(0.68-1.50)$ & 1.00 (reference) & $<0.001$ \\
\hline Model 2 & $1.20(0.81-1.79)$ & $1.53(1.02-2.29)$ & $1.05(0.70-1.58)$ & 1.00 (reference) & $<0.001$ \\
\hline Model 3 & $1.30(0.86-1.98)$ & $1.60(1.05-2.44)$ & $1.24(0.81-1.89)$ & 1.00 (reference) & 0.009 \\
\hline \multicolumn{6}{|l|}{ Niacin } \\
\hline Median intake (mg/day) & 17.7 & 21.6 & 27.9 & 42.8 & \\
\hline No. of cases & 68 & 60 & 54 & 55 & \\
\hline Model 1 & $1.30(0.88-1.92)$ & $1.08(0.73-1.59)$ & $1.02(0.69-1.51)$ & 1.00 (reference) & $<0.001$ \\
\hline Model 2 & $1.40(0.94-2.09)$ & $1.14(0.76-1.70)$ & $0.98(0.65-1.47)$ & 1.00 (reference) & $<0.001$ \\
\hline
\end{tabular}


Table 3 (continued)

\begin{tabular}{|c|c|c|c|c|c|}
\hline & \multicolumn{5}{|c|}{ Quartiles of dietary nutrients ${ }^{b}$} \\
\hline & Q1 & Q2 & Q3 & Q4 & $P$-trend \\
\hline Model 3 & $1.65(1.08-2.51)$ & $1.32(0.87-2.01)$ & $1.09(0.71-1.66)$ & 1.00 (reference) & 0.009 \\
\hline \multicolumn{6}{|l|}{ Dietary fiber } \\
\hline Median intake (g/day) & 27.4 & 34.5 & 43.7 & 63.2 & \\
\hline No. of cases & 68 & 64 & 49 & 56 & \\
\hline Model 1 & $1.23(0.84-1.81)$ & $1.18(0.80-1.73)$ & $0.84(0.56-1.26)$ & 1.00 (reference) & $<0.001$ \\
\hline Model 2 & $1.31(0.88-1.95)$ & $1.18(0.79-1.76)$ & $0.80(0.53-1.22)$ & 1.00 (reference) & $<0.001$ \\
\hline Model 3 & $1.50(0.99-2.27)$ & $1.16(0.76-1.76)$ & $0.87(0.56-1.34)$ & 1.00 (reference) & 0.009 \\
\hline
\end{tabular}

CIN1, cervical intraepithelial neoplasia grade $1 ; \mathrm{Cl}$ confidence interval

${ }^{a}$ Values are $\mathrm{n}$ or ORs ( $95 \% \mathrm{Cls}$ ) obtained from logistic regression analysis, based on the highest intake group as the reference, unless otherwise indicated

b Model 1: odds ratios unadjusted; Model 2: odds ratios adjusted for age, education years, annual family salary, smoker, age at menarche, menopause status, IUD use, years of IUD use, Sexual activity in menstrual period, had gynecologic surgery, had vaginitis; Model 3: additionally odds ratios adjusted for high-risk HPV, SCJ visibility, vaginal $\mathrm{pH}$

c $P$ values for differences between groups were obtained from the Bonferroni correction test for categoric variables

Table 4). The results observed the women of the older, the earlier menarche age, the positive HPV infection, not menopause are more likely to be with the CIN2+ risk. In order to explore that tobacco smoking is one of important factors of CIN risk, the study have done the stratified analyses for association between tobacco smoking and the CIN risk (Additional file 6: Table 5). The sutdy also have done the sensitivity analysis of 2255 non-smoking women smokers in the main analysis for association between tobacco smoking and the CIN risk through the logistic regression analyses by adjusting covariates (Additional file 7: Table 6). The study observe statistically significant associations between tobacco smoking and CIN risk.

\section{Discussion}

The current study investigated the association between dietary nutrient intake and CIN risk in this large-scale population-based study. The results indicated that the intakes of several dietary nutrients such as folate; vitamins B6, C, and $\mathrm{K}$; and niacin were associated with CIN2+ risk.

\section{Multiple micronutrient exposure}

Previous epidemiologic studies have supported the role of diet and nutrition in CIN [14], reporting that low intake levels of fruits and vegetables are associated with cervical cancer risk [45]. In our large sample survey, results found that the median intake level of dietary folate, vitamin $\mathrm{C}$, and vitamin $\mathrm{E}$ in the CIN2+ group $(358.9 \mu \mathrm{g} / \mathrm{d}, 59.4 \mathrm{mg} / \mathrm{d}$, and $8.8 \mathrm{mg} / \mathrm{d}$, respectively) was lower than that recommended by the
Institute of Medicine (IOM) and the joint committee of the World Health Organization and Food and Agricultural Organization of United Nations (WHO/FAO) $(400 \mu \mathrm{g} / \mathrm{d}, 75 \mathrm{mg} / \mathrm{d}$, and $15 \mathrm{mg} / \mathrm{d}$, respectively) $[46,47]$. These results indicate that dietary nutrient intakes have potential effects on CIN risk after adjustment for multiple factors [48].

\section{Folate}

The role of dietary folate in cervical carcinogenesis is still controversial. Previous epidemiologic (case-control) studies reported that dietary folate intake and CIN2+ risk were not related $[49,50]$. However, other studies reported that dietary folate intake was inversely associated with CIN risk [20-22], consistent with our findings. The inconsistencies in the results could be because this study used a large-sample cohort study to obtain results and because the effect of other potential confounders was not evaluated in previous studies. Other factors such as the possibility of inaccurate estimations of food folate composition data or its substantial variations may have also contributed to the same.

Folate plays a role in the de novo synthesis of thymidylate and purines-nucleotides that are required for DNA replication and repair. Folate status affects DNA methylation, both at the gene promoter and genomic levels [51]. Experimental data suggest that the time and dose of folate supplementation during carcinogenesis are important [52]. In this case, the study adjusted for possible risk factors, including the presence of HPV infection, and found that lower dietary folate intake levels were significantly associated with an increasing 
Table 4 ORs and $95 \%$ Cls for quartiles of dietary nutrients intake with cervical intraepithelial neoplasia grade1 risk among 2304 women in the study ${ }^{a}$

\begin{tabular}{|c|c|c|c|c|c|}
\hline & \multicolumn{5}{|c|}{ Quartiles of dietary nutrients ${ }^{\mathbf{b}}$} \\
\hline & Q1 & Q2 & Q3 & Q4 & $P$-trend ${ }^{\mathrm{c}}$ \\
\hline \multicolumn{6}{|l|}{ Folate } \\
\hline Median intake ( $\mu \mathrm{g} /$ day) & 297 & 381 & 488 & 764 & \\
\hline No. of cases & 132 & 147 & 139 & 146 & \\
\hline Model 1 & $0.91(0.69-1.20)$ & $1.01(0.77-1.32)$ & $0.91(0.69-1.19)$ & 1.00 (reference) & $<0.001$ \\
\hline Model 2 & $0.95(0.72-1.26)$ & $1.04(0.79-1.37)$ & $0.92(0.70-1.21)$ & 1.00 (reference) & 0.012 \\
\hline Model 3 & $0.96(0.72-1.27)$ & $1.04(0.79-1.37)$ & $0.91(0.69-1.21)$ & 1.00 (reference) & 0.020 \\
\hline \multicolumn{6}{|l|}{ Vitamin B1 } \\
\hline Median intake (mg/day) & 1.1 & 1.4 & 1.9 & 2.7 & \\
\hline No. of cases & 134 & 157 & 132 & 141 & \\
\hline Model 1 & $0.91(0.68-1.22)$ & $1.25(0.95-1.65)$ & $0.89(0.68-1.15)$ & 1.00 (reference) & $<0.001$ \\
\hline Model 2 & $0.98(0.73-1.31)$ & $1.31(0.99-1.74)$ & $0.89(0.68-1.17)$ & 1.00 (reference) & 0.011 \\
\hline Model 3 & $0.99(0.74-1.34)$ & $1.33(1.00-1.77)$ & $0.91(0.69-1.19)$ & 1.00 (reference) & 0.017 \\
\hline \multicolumn{6}{|l|}{ Vitamin B2 } \\
\hline Median intake (mg/day) & 1.1 & 1.4 & 1.8 & 2.7 & \\
\hline No. of cases & 123 & 148 & 157 & 136 & \\
\hline Model 1 & $0.85(0.64-1.12)$ & $1.13(0.85-1.48)$ & $1.08(0.82-1.42)$ & 1.00 (reference) & $<0.001$ \\
\hline Model 2 & $0.88(0.66-1.17)$ & $1.16(0.88-1.54)$ & $1.09(0.83-1.44)$ & 1.00 (reference) & 0.011 \\
\hline Model 3 & $0.87(0.66-1.17)$ & $1.15(0.86-1.52)$ & $1.10(0.83-1.45)$ & 1.00 (reference) & 0.020 \\
\hline \multicolumn{6}{|l|}{ Vitamin B6 } \\
\hline Median intake (mg/day) & 1.7 & 2.1 & 2.6 & 3.9 & \\
\hline No. of cases & 144 & 146 & 131 & 143 & \\
\hline Model 1 & $1.04(0.79-1.36)$ & $0.99(0.76-1.30)$ & $0.90(0.69-1.19)$ & 1.00 (reference) & $<0.001$ \\
\hline Model 2 & $1.08(0.82-1.43)$ & $1.00(0.76-1.32)$ & $0.90(0.68-1.19)$ & 1.00 (reference) & $<0.001$ \\
\hline Model 3 & $1.09(0.83-1.44)$ & $0.99(0.75-1.31)$ & $0.91(0.69-1.21)$ & 1.00 (reference) & 0.019 \\
\hline \multicolumn{6}{|l|}{ Vitamin C } \\
\hline Median intake (mg/day) & 46.0 & 62.8 & 86.9 & 138.9 & \\
\hline No. of cases & 124 & 149 & 145 & 146 & \\
\hline Model 1 & $0.85(0.65-1.13)$ & $1.05(0.81-1.38)$ & $1.01(0.77-1.33)$ & 1.00 (reference) & $<0.001$ \\
\hline Model 2 & $0.87(0.65-1.16)$ & $1.09(0.83-1.44)$ & $1.04(0.79-1.36)$ & 1.00 (reference) & 0.012 \\
\hline Model 3 & $0.86(0.65-1.15)$ & $1.09(0.83-1.44)$ & $1.04(0.79-1.37)$ & 1.00 (reference) & 0.021 \\
\hline \multicolumn{6}{|l|}{ Vitamin E } \\
\hline Median intake (mg/day) & 4.4 & 8.8 & 10.8 & 21.7 & \\
\hline No. of cases & 131 & 135 & 151 & 147 & \\
\hline Model 1 & $0.83(0.63-1.09)$ & $0.86(0.65-1.13)$ & $1.08(0.83-1.42)$ & 1.00 (reference) & $<0.001$ \\
\hline Model 2 & $0.84(0.63-1.11)$ & $0.88(0.67-1.16)$ & $1.09(0.83-1.44)$ & 1.00 (reference) & 0.013 \\
\hline Model 3 & $0.85(0.64-1.12)$ & $0.87(0.66-1.16)$ & $1.10(0.83-1.45)$ & 1.00 (reference) & 0.023 \\
\hline \multicolumn{6}{|l|}{ Vitamin $\mathrm{K}$} \\
\hline Median intake ( $\mu \mathrm{g} /$ day) & 133.0 & 194.0 & 285.0 & 534.0 & \\
\hline No. of cases & 125 & 159 & 139 & 141 & \\
\hline Model 1 & $0.94(0.71-1.23)$ & $1.23(0.93-1.62)$ & $1.00(0.77-1.31)$ & 1.00 (reference) & $<0.001$ \\
\hline Model 2 & $0.96(0.73-1.27)$ & $1.24(0.94-1.64)$ & $1.01(0.77-1.33)$ & 1.00 (reference) & 0.010 \\
\hline Model 3 & $0.98(0.74-1.29)$ & $1.24(0.94-1.65)$ & $1.03(0.79-1.36)$ & 1.00 (reference) & 0.017 \\
\hline \multicolumn{6}{|l|}{ Niacin } \\
\hline Median intake (mg/day) & 17.7 & 21.6 & 27.9 & 42.8 & \\
\hline No. of cases & 147 & 140 & 135 & 142 & \\
\hline Model 1 & $1.11(0.84-1.46)$ & $0.96(0.73-1.27)$ & $0.96(0.73-1.26)$ & 1.00 (reference) & $<0.001$ \\
\hline Model 2 & $1.14(0.86-1.51)$ & $0.97(0.74-1.28)$ & $0.93(0.71-1.23)$ & 1.00 (reference) & 0.012 \\
\hline
\end{tabular}


Table 4 (continued)

\begin{tabular}{|c|c|c|c|c|c|}
\hline & \multicolumn{5}{|c|}{ Quartiles of dietary nutrients ${ }^{b}$} \\
\hline & $\mathrm{Q1}$ & Q2 & Q3 & Q4 & $P$-trend ${ }^{c}$ \\
\hline Model 3 & $1.15(0.87-1.53)$ & $0.96(0.73-1.26)$ & $0.94(0.72-1.25)$ & 1.00 (reference) & 0.020 \\
\hline \multicolumn{6}{|l|}{ Dietary fiber } \\
\hline Median intake (g/day) & 27.4 & 34.5 & 43.7 & 63.2 & \\
\hline No. of cases & 138 & 148 & 136 & 142 & \\
\hline Model 1 & $0.99(0.75-1.30)$ & $1.07(0.82-1.41)$ & $0.92(0.70-1.21)$ & 1.00 (reference) & $<0.001$ \\
\hline Model 2 & $1.05(0.79-1.39)$ & $1.12(0.85-1.47)$ & $0.93(0.71-1.23)$ & 1.00 (reference) & 0.010 \\
\hline Model 3 & $1.05(0.79-1.39)$ & $1.12(0.85-1.48)$ & $0.95(0.72-1.25)$ & 1.00 (reference) & 0.018 \\
\hline
\end{tabular}

CIN1, cervical intraepithelial neoplasia grade $1 ; \mathrm{Cl}$, confidence interval

${ }^{a}$ Values are $\mathrm{n}$ or ORs ( $95 \% \mathrm{Cls}$ ) obtained from logistic regression analysis, based on the highest intake group as the reference, unless otherwise indicated

b Model 1: odds ratios unadjusted; Model 2: odds ratios adjusted for age, education years, annual family salary, smoker, age at menarche, menopause status, IUD use, years of IUD use, Sexual activity in menstrual period, had gynecologic surgery, had vaginitis; Model 3: additionally odds ratios adjusted for high-risk HPV, SCJ visibility, vaginal $\mathrm{pH}$

c $P$ values for differences between groups were obtained from the Bonferroni correction test for categoric variables

risk of CIN2+. However, it is still not certain if dietary folate is a pathogenetic factor in CIN.

\section{Vitamin B6 and vitamin C}

The role of the dietary intake of vitamin B6 has been investigated in cancer prevention settings. Pre-studies (case-control design) have demonstrated the protective effects of dietary vitamin B6 intake in CIN2+ [20]. While the results of some studies (cohort and laboratory studies) are consistent with those observed in the present study [24], few studies have focused on the relationship between vitamin $\mathrm{B} 6$ and CIN risk. A recent study reported that excessive vitamin $\mathrm{B} 6$ supplementation did not have chemo-preventive effects in cancer and may cause harm [53]. These conflicting results could arise because the aforementioned studies focused on cancers other than those of the cervix. Dietary vitamin B6 intake is an inaccurate biomarker for the evaluation of vitamin B6 levels in the human body, and therefore, cannot accurately represent vitamin B6 levels in cells.

The metabolism of vitamin B6 is required for the synthesis of methionine from homocysteine, required for the methylation of DNA, in order to guarantee genomic stability and gene expression [54]. Existing evidence supports the hypothesis that vitamin B6 deficiency may promote cancer development and progression [55].

Dietary vitamin $C$ intake has a significant role in cervical disease [56]. Pre-studies (case-control studies) have shown that dietary vitamin $\mathrm{C}$ intake and CIN2+ risk are not related $[19,57]$. The findings of recent epidemiologic studies are consistent with those observed in the present study $[15,17,26,27]$. The inconsistencies in the results may have arisen because effects in pre-studies may be modulated by other dietary factors that the study did not focus on. Although dietary vitamin $C$ intake cannot provide precise information on the vitamin $\mathrm{C}$ status in the human body, it could be an appropriate marker for the status of daily vitamin $C$ intake in humans. The conflicting results could have arisen because our study was based on an FFQ, and there was thus a risk of self-report bias, recall bias, or bias arising from assessing food intake based on the amount eaten by other family members. It has been hypothesized that high concentrations of vitamin C may inhibit the GAPDH pathway, leading to an energy crisis in cancer cells [58]. Future research must explore the mechanism of action of such nutrients against cervical cancer.

\section{Niacin, vitamin K, and vitamin B1}

A recent study found that dietary niacin intake had an important role in cancer risk [59]. However, in another study, no association was observed between dietary niacin intake and CIN risk [20]. However, our study results showed that dietary niacin intake was inversely associated with $\mathrm{CIN} 2+$ risk. The inconsistencies in the results could be attributed to the inaccurate assessment of niacin deficiency. A previous study did not consider several factors, such as genetic polymorphism. When measurement errors occur independently of outcomes, there is a tendency that results may be biased toward the null hypothesis [60]. The results found that dietary niacin intake was negatively correlated to CIN2+ risk after adjusting for confounders, including the presence of HPV infection. However, the exact mechanisms remain to be elucidated. The dietary status of niacin has the potential to influence DNA repair, genomic stability, and the immune system, eventually impacting cancer risk. The vitamin also 
participates in a wide variety of ADP-ribosylation reactions [59].

Numerous studies have shown the anticancer effects of vitamin $\mathrm{K}$ and thiamine in various cancers [61]. Our results suggest that dietary vitamin $K$ intake could set a range of carcinogenic doses and therefore would be alert to avoid the risk of carcinogenesis in this dose range. This vitamin has protective effects against $\mathrm{CIN} 2+$ when the dose is optimal. The underlying mechanism of the relationship between vitamin $\mathrm{K}$ intake and CIN risk needs to be further explored. Some studies have found that vitamin B1 has anticancer effects in myeloproliferative neoplasms [62] and oral SCC [63]. Our study results showed that dietary vitamin B1 intake was significantly associated with CIN1 risk. However, it was not significantly associated with CIN2+ risk, and whether vitamin $\mathrm{B} 1$ is significantly associated with the risk of cervical cancer needs to be clarified via results derived from studies with accurate information $[64,65]$.

The study only found vitamin B1 intake to be significantly associated with CIN1 risk. One reason for this could be that CIN1-a low-grade cervical lesion-is highly likely to get resolved. CIN1 presence cannot predict CIN2+ risk. Thus, dietary nutrient intake may be associated with the development of high-grade cervical lesions.

\section{Limits and strengths}

This study has several strengths. First, this populationbased study included the largest sample size so far for the evaluation of the association between dietary nutrition intake and CIN risk, ensuring effective power for the detection of statistical significance. Second, the obtained data on the objective assessments of squamous junction types; vaginal $\mathrm{pH}, \mathrm{HPV}$ types, and CIN-related clinical examinations based on LBC, colposcopy, and colposcopy and cervical biopsy, which may confirm the veracity of the diagnoses from the laboratorial statistics. Third, comprehensive data on potential confounders were also carefully measured and analyzed, minimizing the probability of bias. Finally, the current study analyzed the nature of the dose-response relationships of dietary nutrient intake with CIN1 and CIN2+ risk. However, the study also has some limitations. First, the study had a crosssectional design, and causality could not be standardized. The FFQ was based on screening and the baseline survey of the Shanxi CIN Cohort Study. As there are only 26 items, the FFQ may be limited to broad categories of foods in which the nutrient values precisely reflect the actual intake, given the potential for wide diversity in the actual foods consumed by individual participants in those categories, as a result, the presence of bias cannot be ruled out $[38,41]$. Another limitation was that this study could not evaluate the association between local lifestyle factors that may lead to low dietary intake levels and unhealthy behaviors, and CIN development [66]. Additionally, statistical power of small sample size CIN2+ cases is limited, which may reduces the likelihood that a statistically significant result reflects a true effect. This problem should be addressed with an increasing requirement for strong statistical evidence in the future study.

\section{Conclusions}

In summary, the intakes of dietary nutrients such as folate; vitamins $\mathrm{B} 6, \mathrm{C}$, and $\mathrm{K}$; and niacin were associated with $\mathrm{CIN} 2+$ risk, supporting the hypothesis that nutrients play a role in the development of higher grade $\mathrm{CIN}$ and cervical cancer. Provide dietary measures to preventing CIN.

\section{Supplementary information}

Supplementary information accompanies this paper at https://doi. org/10.1186/s12986-020-00521-4.

Additional file 1: Fig. 1. Design of the reproducibility and validation study. FFQ1 was administered during the first 24-h and FFQ2 was administered during the last $24-h$. The four $24-h$ were administered at intervals of three months.

Additional file 2: Table 1. ORs and $95 \% \mathrm{Cls}$ for quartiles of dietary nutrients intake with with risk of cervical intraepithelial neoplasia grades 2 and above among 2304 women in the study.

Additional file 3: Table 2. ORs and 95\% Cls for quartiles of dietary nutrients intake with cervical intraepithelial neoplasia risk among 2304 women in the study.

Additional file 4: Table 3. Reliability and validity of food-frequency questionnaires $^{\mathrm{a}}$ (24-h, FFQ1 and FFQ2) in 218 women in China.

Additional file 5: Table 4. ORs and 95\% Cls for the associations between Age, Age at menarche, Menopause status and high-risk HPV infection with the risk of cervical intraepithelial neoplasia grades 2 and above.

Additional file 6: Table 5. ORs and 95\% Cls for the associations between tobacco smoking with the risk of cervical intraepithelial neoplasia among 2304 women in the study.

Additional file 7: Table 6. ORs and 95\% Cls for quartiles of dietary nutrients intake with risk of cervical intraepithelial neoplasia grades 2 and above among participants among 2255 non-smoking women in the study.

\section{Abbreviations}

ASC-US: Atypical squamous cells of undetermined significance; CIN: Cervical intraepithelial neoplasia; CIN1: Cervical intraepithelial neoplasia grade 1; CIN2: Cervical intraepithelial neoplasia grade 2; CIN3: Cervical intraepithelial neoplasia grade 3; ECC: Endocervical curettage; HPV: Human papillomavirus; LBC: Liquid based cytology; SCC: Squamous cell carcinoma; FFQ: Food frequency questionnaire; IUD: Intrauterine device; SCJ: Squamous-columnar junction; TBS: The Bethesda system.

\section{Acknowledgements}

We thank the help that investigators and local healthcare workers from the Jiexiu Family Planning/Women and Children Health Service Center and Yangqu County Hospital supplied. 


\section{Authors' contributions}

The authors' contributions were as follows-Min Hao: designed, supervised and guided the study; Zhe Wang, Aimin Yang: conducted the statistical analysis and wrote the manuscript; Jing Yang and Weihong Zhao: wrote and revised the manuscript; and all authors: contributed to the design of the statistical analysis, interpreted data, critiqued and revised the manuscript. All authors read and approved the final manuscript.

\section{Funding}

This study is supported by the Special Public Welfare Industry Research of National Health and Family Planning Commission of China (Grant 201402010); This study is supported by the applied basic research project of Shanxi province (Grant 201601D011086); This study is supported by the scientific research project of Shanxi provincial Health Planning Commission: Based on the regional factors of the high incidence of cervical cancer in Shanxi province (Grant 2018GW04); This study is supported by the National Natural Science Foundation of China (81972452); This study is supported by the Key research and development project of Shanxi province (Grant 201803D31121).

\section{Availability of data and materials}

The datasets generated and/or analyzed during the current study are not publicly available due to privacy protection of the participants but are available from the corresponding author on reasonable request.

\section{Ethics approval and consent to participate}

The study was approved by the ethics committee of the Second Hospital, Shanxi Medical University and written informed consent was obtained from the participants. The study was performed in accordance with the Declaration of Helsinki.

\section{Consent for publication}

Not applicable.

\section{Competing interests}

The authors declare that they have no competing interests.

\section{Author details}

1 Department of Obstetrics and Gynecology, Second Hospital of Shanxi Medical University, 382 Wuyi Rd, Taiyuan 030001, Shanxi, China. ${ }^{2}$ Hong Kong Institute of Diabetes and Obesity, The Chinese University of Hong Kong, Sha Tin, Hong Kong SAR. ${ }^{3}$ Department of Epidemiology, School of Public Health, Shanxi Medical University, Taiyuan, China. ${ }^{4}$ Department of Obstetrics and Gynecology, Affiliated Hospital of Inner Mongolia Medical University, Huhhot, China. ${ }^{5}$ Department of Obstetrics and Gynecology, Affiliated Tumor Hospital of Guangxi Medical University, Nanning, China. ${ }^{6}$ Department of Gynecologic Oncology, Women's Hospital, School of Medicine, Zhejiang University, Hangzhou, Zhejiang, China. ${ }^{7}$ Department of Pathology, Second Hospital of Shanxi Medical University, Taiyuan 030001, Shanxi, China.

Received: 9 April 2020 Accepted: 29 October 2020

Published online: 30 November 2020

\section{References}

1. Ferlay J, Soerjomataram I, Dikshit R, Eser S, Mathers C, Rebelo M, Parkin DM, Forman D, Bray F. Cancer incidence and mortality worldwide: sources, methods and major patterns in GLOBOCAN 2012. Int J Cancer. 2015;136:E359-386.

2. Torre LA, Bray F, Siegel RL, Ferlay J, Lortettieulent J, Jemal A: GLOBOCAN 2012: Estimated Cancer Incidence Mortality and Prevalence Worldwide in 2012. 2015

3. Newman PA, Logie CH, Lacombe-Duncan A, Baiden P, Tepjan S, Rubincam C, Doukas N, Asey F. Parents' uptake of human papillomavirus vaccines for their children: a systematic review and meta-analysis of observational studies. BMJ Open. 2018;8:e019206.

4. Hernandez BY, McDuffie K, Wilkens LR, Kamemoto L, Goodman MT. Diet and premalignant lesions of the cervix: evidence of a protective role for folate, riboflavin, thiamin, and vitamin B12. Cancer Causes Control. 2003;14:859-70.
5. Gillet E, Meys JF, Verstraelen $H$, Verhelst $R$, De Sutter P, Temmerman M, Vanden Broeck D. Association between bacterial vaginosis and cervical intraepithelial neoplasia: systematic review and meta-analysis. PLoS ONE. 2012; 7:e45201.

6. Vesco KK, Whitlock EP, Eder M, Burda BU, Senger CA, Lutz K. Risk factors and other epidemiologic considerations for cervical cancer screening: a narrative review for the U.S. Preventive Services Task Force. Ann Intern Med. 2011;155:698-705, w216.

7. Schiffman M, Castle PE, Jeronimo J, Rodriquez AC, Wacholder S. Human papillomavirus and cervical cancer. Lancet. 2007;370:890-907.

8. Borderud SP, Li Y, Burkhalter JE, Sheffer CE, Ostroff JS. Erratum: Electronic cigarette use among patients with cancer: characteristics of electronic cigarette users and their smoking cessation outcomes. Cancer. 2015;121:800. https://doi.org/10.1002/cncr.28811.

9. Castellsague X, Diaz M, de Sanjose S, Munoz N, Herrero R, Franceschi S, Peeling RW, Ashley R, Smith JS, Snijders PJ, et al. Worldwide human papillomavirus etiology of cervical adenocarcinoma and its cofactors: implications for screening and prevention. J Natl Cancer Inst. 2006;98:303-15.

10. Cervical carcinoma and reproductive factors: collaborative reanalysis of individual data on 16,563 women with cervical carcinoma and 33,542 women without cervical carcinoma from 25 epidemiological studies. Int J Cancer 2006, 119:1108-1124.

11. Munoz N, Franceschi S, Bosetti C, Moreno V, Herrero R, Smith JS, Shah KV, Meijer CJ, Bosch FX. Role of parity and human papillomavirus in cervical cancer: the IARC multicentric case-control study. Lancet. 2002;359:1093-101.

12. Appleby P, Beral V, Berrington de Gonzalez A, Colin D, Franceschi S, Goodill A, Green J, Peto J, Plummer M. Sweetland S (2006) Carcinoma of the cervix and tobacco smoking: collaborative reanalysis of individual data on 13,541 women with carcinoma of the cervix and 23,017 women without carcinoma of the cervix from 23 epidemiological studies. Int J Cancer. 2006;118:1481-95.

13. Plummer M, Herrero R, Franceschi S, Meijer CJ, Snijders P, Bosch FX, de Sanjose S, Munoz N. Smoking and cervical cancer: pooled analysis of the IARC multi-centric case-control study. Cancer Causes Control. 2003;14:805-14.

14. Garcia-Closas R, Castellsague X, Bosch X, Gonzalez CA. The role of diet and nutrition in cervical carcinogenesis: a review of recent evidence. Int J Cancer. 2005;117:629-37.

15. Gonzalez CA, Travier N, Lujan-Barroso L, Castellsague X, Bosch FX, Roura E, Bueno-de-Mesquita HB, Palli D, Boeing H, Pala V, et al. Dietary factors and in situ and invasive cervical cancer risk in the European prospective investigation into cancer and nutrition study. Int J Cancer. 2011;129:449-59.

16. Chih HJ, Lee AH, Colville L, Binns CW, Xu D. A review of dietary prevention of human papillomavirus-related infection of the cervix and cervical intraepithelial neoplasia. Nutr Cancer. 2013;65:317-28.

17. Ghosh C, Baker JA, Moysich KB, Rivera R, Brasure JR, McCann SE. Dietary intakes of selected nutrients and food groups and risk of cervical cancer. Nutr Cancer. 2008;60:331-41.

18. Ducker GS, Rabinowitz JD. One-Carbon Metabolism in Health and Disease. Cell Metab. 2017;25:27-42.

19. Wideroff L, Potischman N, Glass AG, Greer CE, Manos MM, Scott DR, Burk RD, Sherman ME, Wacholder S, Schiffman M. A nested case-control study of dietary factors and the risk of incident cytological abnormalities of the cervix. Nutr Cancer. 1998;30:130-6.

20. Goodman MT, McDuffie K, Hernandez B, Wilkens LR, Bertram CC, Killeen J, Le Marchand L, Selhub J, Murphy S, Donlon TA. Association of methylenetetrahydrofolate reductase polymorphism C677T and dietary folate with the risk of cervical dysplasia. Cancer Epidemiol Biomarkers Prev. 2001;10:1275-80

21. Zhao W, Hao M, Wang Y, Feng N, Wang Z, Wang W, Wang J, Ding L. Association between folate status and cervical intraepithelial neoplasia. Eur J Clin Nutr. 2016;70:837-42.

22. Piyathilake CJ, Ollberding NJ, Kumar R, Macaluso M, Alvarez RD, Morrow CD. Cervical microbiota associated with higher grade cervical intraepithelial neoplasia in women infected with high-risk human papillomaviruses. Cancer Prev Res (Phila). 2016;9:357-66.

23. Rimando AM, Suh N. Natural products and dietary prevention of cancer. Mol Nutr Food Res. 2008;52(Suppl 1):S5.

24. Tomita LY, D'Almeida V, Villa LL, Franco EL, Cardoso MA. Polymorphisms in genes involved in folate metabolism modify the association of dietary 
and circulating folate and vitamin B-6 with cervical neoplasia. J Nutr. 2013;143:2007-14.

25. VanEenwyk J, Davis FG, Colman N. Folate, vitamin C, and cervical intraepithelial neoplasia. Cancer Epidemiol Biomarkers Prev. 1992;1:119-24.

26. Lee GJ, Chung HW, Lee KH, Ahn HS. Antioxidant vitamins and lipid peroxidation in patients with cervical intraepithelial neoplasia. J Korean Med Sci. 2005;20:267-72

27. Giuliano AR, Siegel EM, Roe DJ, Ferreira S, Baggio ML, Galan L, DuarteFranco E, Villa LL, Rohan TE, Marshall JR, Franco EL. Dietary intake and risk of persistent human papillomavirus (HPV) infection: the Ludwig-McGill HPV Natural History Study. J Infect Dis. 2003;188:1508-16.

28. Kitano T, Yoda H, Tabata K, Miura M, Toriyama M, Motohashi S, Suzuki T. Vitamin $\mathrm{K} 3$ analogs induce selective tumor cytotoxicity in neuroblastoma. Biol Pharm Bull. 2012;35:617-23.

29. Yang CR, Liao WS, Wu YH, Murugan K, Chen C, Chao Jl. CR108, a novel vitamin $\mathrm{K} 3$ derivative induces apoptosis and breast tumor inhibition by reactive oxygen species and mitochondrial dysfunction. Toxicol Appl Pharmacol. 2013;273:611-22.

30. de Carvalho Scharf Santana N, Lima NA, Desoti VC, Bidoia DL, de Souza Bonfim Mendonca P, Ratti BA, Nakamura TU, Nakamura CV, Consolaro ME, Ximenes VF, de Oliveira Silva S. Vitamin K3 induces antiproliferative effect in cervical epithelial cells transformed by HPV 16 (SiHa cells) through the increase in reactive oxygen species production. Arch Gynecol Obstet. 2016;294:797-804.

31. Park SM, LiT, Wu S, Li WQ, Weinstock M, Qureshi AA, Cho E. Niacin intake and risk of skin cancer in US women and men. Int J Cancer. 2017:140:2023-31.

32. Sen U, Shenoy PS, Bose B. Opposing effects of low versus high concentrations of water soluble vitamins/dietary ingredients Vitamin $C$ and niacin on colon cancer stem cells (CSCs). Cell Biol Int. 2017:41:1127-45.

33. Chen W, Zheng R, Baade PD, Zhang S, Zeng H, Bray F, Jemal A, Yu XQ, He J. Cancer statistics in China, 2015. CA Cancer J Clin. 2016;66:115-32.

34. Wang JT, Ma XC, Cheng YY, Ding L, Zhou Q. A case-control study on the association between folate and cervical cancer. Zhonghua Liu Xing Bing Xue Za Zhi. 2006:27:424-7.

35. Wang Z, Wang J, Fan J, Zhao W, Yang X, Wu L, Li D, Ding L, Wang W, Xu J, et al. Risk factors for cervical intraepithelial neoplasia and cervical cancer in Chinese women: large study in Jiexiu, Shanxi Province, China. J Cancer. 2017;8:924-32.

36. Yang J, Yang A, Wang Z, Wang W, Wang Z, Wang Y, Wang J, Song J, Li L, LV $W$, et al. Interactions between serum folate and human papillomavirus with cervical intraepithelial neoplasia risk in a Chinese population-based study. Am J Clin Nutr. 2018;108:1034-42.

37. Huppert JS, Bates JR, Weber AF, Quinn N, Gaydos CA. Abnormal vaginal $\mathrm{pH}$ and Mycoplasma genitalium infection. J Pediatr Adolesc Gynecol. 2013:26:36-9.

38. Shi Z, Taylor AW, Riley M, Byles J, Liu J, Noakes M. Association between dietary patterns, cadmium intake and chronic kidney disease among adults. Clin Nutr. 2018;37:276-84.

39. Yuan S, Yu HJ, Liu MW, Huang Y, Yang XH, Tang BW, Song Y, Cao ZK, Wu HJ, He QQ, Gasevic D. The association of fruit and vegetable consumption with changes in weight and body mass index in Chinese adults: a cohort study. Public Health. 2018:157:121-6.

40. Zhai FY, Du SF, Wang ZH, Zhang JG, Du WW, Popkin BM. Dynamics of the Chinese diet and the role of urbanicity, 1991-2011. Obes Rev. 2014;15(Suppl 1):16-26.

41. Subar AF, Midthune D, Kulldorff M, Brown CC, Thompson FE, Kipnis V, Schatzkin A. Evaluation of alternative approaches to assign nutrient values to food groups in food frequency questionnaires. Am J Epidemiol. 2000:152:279-86.

42. Gong W, Liu A, Yao Y, Ma Y, Ding C, Song C, Yuan F, Zhang Y, Feng G, Chen Z, Ding G. Nutrient supplement use among the Chinese population: a cross-sectional study of the $2010(-) 2012$ China Nutrition and Health Surveillance. Nutrients. 2018:10:1733.

43. Xu L, Dibley MJ, D'Este C. Reliability and validity of a food-frequency questionnaire for Chinese postmenopausal women. Public Health Nutr. 2004;7:91-8.

44. Zhuang M, Yuan Z, Lin L, Hu B, Wang X, Yang Y, Chen X, Jin L, Lu M, Ye W. Reproducibility and relative validity of a food frequency questionnaire developed for adults in Taizhou, China. PLoS ONE. 2012;7:e48341.

45. Potischman N, Brinton LA. Nutrition and cervical neoplasia. Cancer Causes Control. 1996;7:113-26.
46. Glade MJ. Workshop on folate, B12, and choline. Sponsored by the Panel on Folate and Other B Vitamins of the Standing Committee on the Scientific Evaluation of Dietary Reference Intakes, Food and Nutrition Board, Institute of Medicine, Washington, D.C., March 3-4, 1997. Nutrition. 1999;15:92-6.

47. Antioxidants IOMPoD, compounds R: dietary reference intakes for vitamin C, vitamin E, selenium, and carotenoids. National Academies Press 2000.

48. Nutritional aspects of the development of cancer. Report of the Working Group on Diet and Cancer of the Committee on Medical Aspects of Food and Nutrition Policy. Rep Health Soc Subj 1998;48:i.

49. Childers JM, Chu J, Voigt LF, Feigl P, Tamimi HK, Franklin EW, Alberts DS, Meyskens FL Jr. Chemoprevention of cervical cancer with folic acid: a phase III Southwest Oncology Group Intergroup study. Cancer Epidemiol Biomarkers Prev. 1995:4:155-9.

50. Butterworth CE Jr, Hatch KD, Soong SJ, Cole P, Tamura T, Sauberlich HE, Borst M, Macaluso M, Baker V. Oral folic acid supplementation for cervical dysplasia: a clinical intervention trial. Am J Obstet Gynecol. 1992;166:803-9.

51. Ulrich CM. Folate and cancer prevention: a closer look at a complex picture. Am J Clin Nutr. 2007:86:271-3.

52. Kim YI. Folate: a magic bullet or a double edged sword for colorectal cancer prevention? Gut. 2006;55:1387-9.

53. Brasky TM, White $\mathrm{E}$, Chen CL. Long-term, supplemental, one-carbon metabolism-related vitamin B use in relation to lung cancer risk in the vitamins and lifestyle (VITAL) cohort. J Clin Oncol. 2017:35:3440-8.

54. Selhub J. Folate, vitamin B12 and vitamin B6 and one carbon metabolism. J Nutr Health Aging. 2002;6:39-42.

55. Galluzzi L, Vacchelli E, Michels J, Garcia P, Kepp O, Senovilla L, Vitale I, Kroemer G. Effects of vitamin B6 metabolism on oncogenesis, tumor progression and therapeutic responses. Oncogene. 2013;32:4995-5004.

56. Leekha A, Gurjar BS, Tyagi A, Rizvi MA, Verma AK. Vitamin C in synergism with cisplatin induces cell death in cervical cancer cells through altered redox cycling and p53 upregulation. J Cancer Res Clin Oncol. 2016;142:2503-14.

57. Kjellberg L, Hallmans G, Ahren AM, Johansson R, Bergman F, Wadell G, Angstrom T, Dillner J. Smoking, diet, pregnancy and oral contraceptive use as risk factors for cervical intra-epithelial neoplasia in relation to human papillomavirus infection. Br J Cancer. 2000;82:1332-8.

58. Yun J, Mullarky E, Lu C, Bosch KN, Kavalier A, Rivera K, Roper J, Chio II, Giannopoulou EG, Rago C, et al. Vitamin C selectively kills KRAS and BRAF mutant colorectal cancer cells by targeting GAPDH. Science. 2015:350:1391-6.

59. Kirkland JB. Niacin and carcinogenesis. Nutr Cancer. 2003;46:110-8.

60. Giovannucci E, Stampfer MJ, Colditz GA, Hunter DJ, Fuchs C, Rosner BA, Speizer FE, Willett WC. Multivitamin use, folate, and colon cancer in women in the Nurses' Health Study. Ann Intern Med. 1998;129:517-24.

61. Wang Z, Ge L, Wang M, Carr BI. Grb2-associated binder-1 plays a central role in the hepatocyte growth factor enhancement of hepatoma growth inhibition by K vitamin analog compound 5 . Hepatology. 2007:46:2003-13.

62. Curto-Garcia N, Harrison CN, McLornan DP, Radia DH. Thiamine deficiency appears uncommon in patients with Myeloproliferative Neoplasms. Br J Haematol. 2017:178:338-40

63. Grimm M, Calgeer B, Teriete P, Biegner T, Munz A, Reinert S. Targeting thiamine-dependent enzymes for metabolic therapies in oral squamous cell carcinoma? Clin Transl Oncol. 2016;18:196-205.

64. Sweet R, Paul A, Zastre J. Hypoxia induced upregulation and function of the thiamine transporter, SLC19A3 in a breast cancer cell line. Cancer Biol Ther. 2010;10:1101-11.

65. Zastre JA, Sweet RL, Hanberry BS, Ye S. Linking vitamin B1 with cancer cell metabolism. Cancer Metab. 2013;1:16.

66. Xiao Q, Freedman ND, Ren J, Hollenbeck AR, Abnet CC, Park Y. Intakes of folate, methionine, vitamin B6, and vitamin B12 with risk of esophageal and gastric cancer in a large cohort study. Br J Cancer. 2014;1 10:1328-33.

\section{Publisher's Note}

Springer Nature remains neutral with regard to jurisdictional claims in published maps and institutional affiliations. 